\title{
Proposta para adoção do Target Value Design (TVD) na gestão do processo de projeto de empreendimentos imobiliários
}

\author{
Proposal for Target Value Design adoption into the design \\ management of real estate products
}

\section{Carolina Asensio Oliva Ariovaldo Denis Granja}

\section{Resumo \\ A}

entrega do produto com maior valor agregado por meio da elaboração do projeto esbarra nas restrições estabelecidas pelas partes interessadas (incorporadoras, empreiteiras, subempreiteiras e clientes finais). Essas dificuldades se exacerbam tendo em vista as dificuldades impostas por um processo de desenvolvimento de produtos fragmentado, que dificulta práticas colaborativas. Além disso, objetivos, meios e restrições mudam durante o projeto até que todos estejam alinhados e consistentes entre si. Essas características fazem da aplicação do Target Value Design (TVD) uma oportunidade para promover mudanças na gestão do processo de projeto tradicional, com vistas a entregar produtos com maior valor agregado e a promover o custo como parâmetro indutor de criatividade. O objetivo desta pesquisa foi elaborar uma proposta para adoção do TVD na gestão do processo de projeto de produtos imobiliários no Brasil. Como estratégia de pesquisa adotou-se o estudo de caso exploratório, com dados coletados em um escritório de arquitetura e em duas construtoras/incorporadoras. Como resultado a pesquisa apresenta uma proposta para adoção e implantação do TVD no contexto analisado que leva em consideração níveis evolutivos de colaboração entre os agentes envolvidos no processo. A pesquisa tem orientação exploratória, visa à contribuição teórica e abre novas oportunidades de pesquisa na temática do TVD.

Palavras-chaves: Target Value Design. Gestão do processo de projeto. Colaboração. Práticas colaborativas. Mercado imobiliário.

\begin{abstract}
The delivery of high value-added products is made difficult by restrictions imposed by the project's participants (building companies, contractor, subcontractors and final users). These difficulties are exacerbated by a highly fragmented product development process, in which individual interests can pose obstacles for the collaboration between all involved. Furthermore, objectives, means and restrictions change during project definition until the objectives and restrictions are aligned and consistent with one another. These characteristics indicate that Target Value Design (TVD) can be an important tool to stimulate changes in traditional design process management. The aim of this study was to develop a proposal for the inclusion of TVD in the design management process for real estate products in Brazil. An exploratory case study was made, and the data were collected in an architecture firm and two property and building companies. As a result, a proposal for the inclusion of TVD was formulated, taking into account evolutionary levels of collaboration between projects' participants. This is an exploratory study that seeks to give a theoretical contribution and to open new opportunities of research about TVD.
\end{abstract}

Carolina Asensio Oliva Universidade Estadual de Campinas Campinas - SP - Brasil

Ariovaldo Denis Granja Universidade Estadual de Campinas Campinas - SP - Brasil

Recebido em 25/11/14 Aceito em 02/06/15
Keywords: Target Value Design. Design process management. Collaboration. Construction industry. Real estate. 


\section{Introdução}

Nos últimos anos o Brasil tem experimentado um crescimento de lançamentos imobiliários. Esses produtos são frequentemente caracterizados por elevadas restrições orçamentárias, processos de projeto fragmentados e relações de adversidade entre as partes interessadas, que levam muitas vezes à sobreposição de interesses individuais e sacrificam a qualidade do produto final, pois as expectativas financeiras precisam ser salvaguardadas. Somam-se a esses fatores grandes desperdícios de tempo na forma de retrabalhos, tanto nas fases de projeto como nas de execução. Como resultado comumente se colocam em dúvida a qualidade final e o atendimento das expectativas dos produtos entregues aos clientes e usuários finais, uma vez que reduções de escopo e subespecificações podem ocorrer.

A filosofia lean tem como base conceitual a eliminação de desperdícios (WOMACK; JONES; ROOS, 2004), e um dos métodos que a integra é o custeio-meta (CM) (target costing). O processo de gerenciamento de custos tradicional determina o custo do produto baseado no projeto e no custo estimado de produção, enquanto o $\mathrm{CM}$ propõe o inverso: o custo se torna um parâmetro inicial de projeto, não sendo mais considerado uma mera consequência dele. Assim, a integração dessa lógica ao processo de projeto pode se constituir em um importante elemento para uma estratégia lean de gestão de processo de projeto (lean design management) (EMMITT, 2011).

Não raro custos e restrições de projeto são encarados como entraves ao processo criativo de produtos destinados à construção civil. No entanto, as restrições orçamentárias não necessariamente implicam sacrifícios à estética e à qualidade do produto final (RYBKOWSKI et al., 2011). De acordo com essa perspectiva, a adoção do CM na gestão do processo de projeto pode ser assimilada como um indutor de criatividade e inovação. Assim, no CM os atributos de qualidade e funcionalidade representativos de valor na percepção do cliente ou usuário final precisam ser preservados, pressupondo um ambiente colaborativo (ZIMINA; BALLARD; PASQUIRE, 2012).

Nos EUA a abordagem do TVD tem sido proposta como uma adaptação do CM para a construção civil (RYBKOWSKI et al., 2011; ZIMINA; BALLARD; PASQUIRE, 2012). O TVD tem como princípio utilizar o valor na perspectiva do cliente como elemento norteador do processo de projeto, reduzindo dessa forma os desperdícios e atendendo, ou mesmo excedendo, as expectativas do cliente (ZIMINA; BALLARD; PASQUIRE,
2012). Além disso, o TVD pressupõe a adoção de práticas integradas de projeto, tais como o Integrated Project Delivery (IPD) (AMERICAN..., 2007).

Contrariamente aos princípios do TVD, uma das práticas frequentes no processo de projeto tradicional é a participação tardia dos fornecedores e prestadores de serviços, apenas quando o projeto já se encontra bastante adiantado. O resultado é uma alta fragmentação no processo de projeto. A incorporadora ou construtora contrata os diferentes projetistas em etapas diversas do processo, bem como a equipe responsável pela execução do empreendimento, criando-se um ciclo de não colaboração e desconexão, em que a integração dos agentes é pequena (MELHADO et al., 2006). Por outro lado, o TVD propicia que essas alternativas sejam consideradas durante o processo de projeto, uma vez que a interdisciplinaridade e a colaboração entre os agentes são estabelecidas desde as etapas mais precoces de desenvolvimento do produto.

Até o momento, nos EUA os melhores resultados de uso do TVD foram obtidos no contexto de empreendimentos hospitalares como referencial teórico para a gestão do processo de projeto de forma integrada. Os resultados dessas implantações têm reduzido a probabilidade de desvios de custos, mantendo os requisitos de valor na perspectiva dos clientes (BALLARD; REISER, 2004; MACOMBER; HOWELL; BARBERIO, 2007; BALLARD, 2011; RYBKOWSKI et al, 2011; ZIMINA; BALLARD; PASQUIRE, 2012; DENEROLLE, 2013; DO; BALLARD; TOMMELEIN, 2014).

Em que pese a esses resultados positivos nos EUA, ainda não há evidências de que o referencial teórico de TVD, ainda em estruturação e evolução, é suficiente para generalizar resultados para outros países e contextos. Como interesse particular desta pesquisa até a data presente não se tem conhecimento de sua aplicação consciente e sistemática no contexto de desenvolvimento de produtos e na gestão do processo de projeto de empreendimentos imobiliários, ou seja, aqueles destinados à venda no mercado (ROCHA LIMA JUNIOR, 1994). Sendo assim, a questão que motivou esta pesquisa foi: "Como incorporar o TVD no processo de desenvolvimento de produto, particularmente na gestão do processo de projeto de empreendimentos imobiliários?". Decorre como objetivo elaborar uma proposta para adoção do TVD na gestão do processo de projeto de produtos imobiliários. Partiu-se da premissa de que níveis crescentes de adoção de práticas colaborativas 
nesse processo (AMERICAN..., 2007) conduzirão a uma aplicação de pleno potencial do TVD. Como resultado apresenta-se uma proposta para integração dessa abordagem na gestão do processo de projeto com base em evidências de estudo de caso exploratório em um escritório de arquitetura e em duas construtoras/incorporadoras nacionais, considerando-se os níveis de colaboração detectados no processo de projeto de tais empresas.

\section{Custeio-meta e Target Value Design}

O CM é um processo estratégico de gerenciamento de custos e margens (ANSARI; BELL, 1997). As raízes intelectuais do $\mathrm{CM}$ encontram-se na teoria dos sistemas abertos (open systems theory), que reconhece que é mais vantajoso se gerenciarem os sistemas de forma proativa antes que se desviem de seus cursos pretendidos, em vez de se tomar medidas corretivas após os desvios terem ocorrido (ANSARI; BELL, 1997). Seis princípios norteiam o CM (ANSARI; BELL, 1997):

(a) preços do mercado determinam planos para lançamentos de novos produtos;

(b) foco no cliente/consumidor;

(c) foco no desenvolvimento de produtos e processos;

(d) equipes interdisciplinares;

(e) redução de custos ao longo do ciclo de vida; e

(f) envolvimento da cadeia de valor

Para muitos autores o CM tem suas origens na indústria automobilística japonesa no início dos anos 1960, na forma de uma estratégia de redução de custos e manutenção dos resultados esperados (COOPER; SLAGMULDER, 1997; LIKER, 2004; JACOMIT; GRANJA, 2011). Na gestão tradicional o custo é baseado nas atividades de produção com base no projeto detalhado para execução. O CM inverte esta lógica: o custo do produto é determinado em etapas precoces de definição do produto; e seu custo é baseado nas necessidades do cliente com relação às funções que o produto precisa desempenhar e quanto o cliente pode e está disposto a pagar por elas (COOPER; SLAGMULDER, 1997; LIKER, 2004; PENNANEN; BALLARD; HAAHTELA, 2010).

Por sua vez, o TVD vem sendo reivindicado nos EUA como uma adaptação do CM para as particularidades da indústria da construção civil
(MACOMBER; HOWELL; BARBERIO, 2007). $\mathrm{O}$ argumento apresentado para a necessidade dessa adaptação intersetorial é o de que o TVD retrata a construção civil como um sistema complexo, baseado em projetos (empreendimentos), que inclui:

(a) a definição do produto;

(b) o empreendimento e suas fases de execução; e

(c) a entrega de maior valor agregado aos usuários finais, por meio de melhoria contínua e eliminação de desperdícios (MACOMBER; HOWELL; BARBERIO, 2007).

A abordagem do TVD é baseada nos princípios do Integrated Project Delivery (IPD) (AMERICAN..., 2007). O IPD é um processo de projeto integrado que utiliza os conhecimentos e as especialidades de cada membro da equipe, visando às melhores soluções de forma integrada já nas fases iniciais de concepção (AMERICAN..., 2007). No IPD todos os envolvidos com o processo de desenvolvimento de produto trabalham de forma colaborativa como uma única equipe em prol do empreendimento como um todo, o que pode representar um grande desafio (ZIMINA; BALLARD; PASQUIRE, 2012). A Figura 1 ilustra as diferenças entre o processo tradicional e o IPD.

O IPD utiliza um sistema de contratos multipartes (Integrated Form of Agreement - IFoA) como uma de suas ferramentas para atingir níveis de colaboração adequados entre os agentes desde o início do processo. No IFoA constam os objetivos do projeto, como ele será conduzido e os riscos que serão assumidos. Esse instrumento é então assinado pelo responsável pelo projeto de arquitetura, proprietário e empreiteira (LICHTIG, 2006). No Brasil não se tem notícia do uso desses tipos de contratos integrados, com divisão de riscos e benefícios entre as partes interessadas do empreendimento, de forma a incentivar o comprometimento e a colaboração já nas primeiras etapas de desenvolvimento de um produto.

Para maior efetividade, em geral o TVD assume que o produto está inserido num contexto de IPD, reconhecido como uma ferramenta de entrega do produto (project delivery) de modo amplo (DENEROLLE, 2013). Com base nisso, o Project Production Systems Laboratory ( $\left.{ }^{2} \mathrm{SL}\right)$ da Universidade da Califórnia, em Berkeley, estabelece 17 princípios que direcionam a aplicação do TVD, conforme o estágio atual de seu desenvolvimento (BALLARD, 2011) (Quadro 1). 
Figura 1 - Processo de projeto tradicional e o IPD
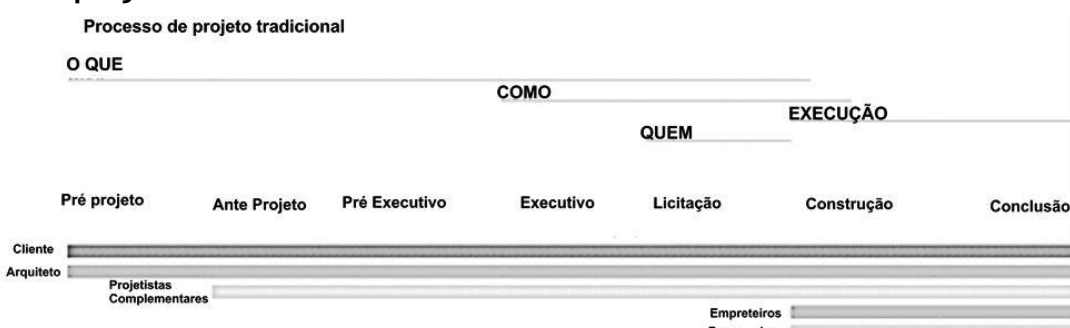

Processo de projeto integrado (IPD)

OQUE

сомо

QUEM

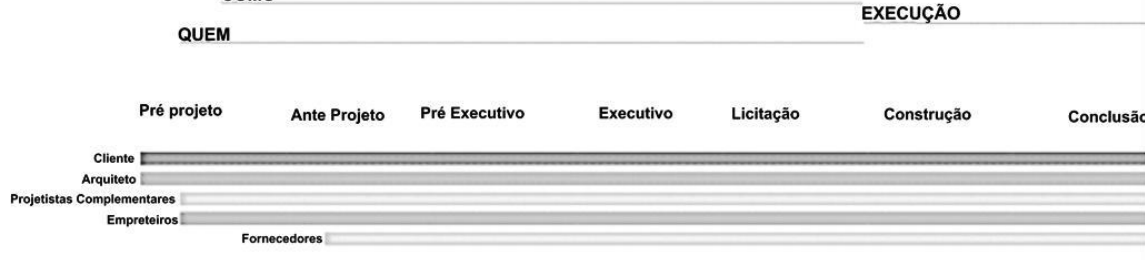

Fonte: adaptado de American Institute of Architects (2007).

\section{Quadro 1 - Resumo dos 17 princípios do TVD}

1 Com o auxílio dos prestadores de serviços principais, o cliente desenvolve e avalia o estudo de caso do empreendimento e decide se deve financiar um estudo de viabilidade, em parte baseado na lacuna entre o custo permissível de projeto e o custo de mercado.

2 O estudo de caso do empreendimento é baseado na previsão do custo do ciclo de vida do edifício e benefícios, preferivelmente derivado de um modelo de operação. Ele inclui a especificação do custo permissível - quanto o usuário quer e está disposto a pagar. Restrições orçamentárias são especificadas, tais como as limitações do usuário na sua habilidade de pagar o requerido investimento para obter estes benefícios.

3 O estudo de viabilidade envolve todos os membros-chaves (projetistas, construtores, partes interessadas do cliente) na equipe que irá entregar o projeto.

$4 \quad$ A viabilidade é avaliada por meio do alinhamento de fins (o que se quer), meios (projeto conceitual) e restrições (custo, tempo etc.). O projeto é aprovado somente se este alinhamento é alcançado ou possível de ser alcançado durante o processo de projeto

5 O estudo de viabilidade produz um orçamento detalhado e cronograma, alinhados com escopo e parâmetros de qualidade.

$6 \quad$ O cliente é membro ativo e permanente de entrega de projeto.

7 Todos os membros da equipe entendem o empreendimento e os valores das partes interessadas.

8 Algumas formas de contratos relacionais são usadas para alinhar interesses dos membros da equipe de projeto com os objetivos do projeto.

9 Regra cardinal: metas de custos e cronograma não podem ser excedidas, e somente o cliente pode alterar o escopo, qualidade, custo ou cronograma.

10 Implicações de custo, qualidade e cronograma em soluções alternativas de projeto são discutidas pelos membros da equipe antes de grandes investimentos da equipe de projeto.

11 Estimativas de custos e orçamento são feitas continuamente por meio de colaboração verdadeira entre os membros da equipe de projetos.

12 O sistema Last Planner é utilizado para coordenar ações entre a equipe.

13 As metas são estabelecidas como objetivos flexíveis, a fim de estimular inovação.

14 Metas de escopo e custo são alocadas por intermédio das equipes de TVD multidisciplinares, tipicamente divididas em sistemas: estrutural, hidráulica, elétrica etc.

15 A estimativa de custos das equipes (custos alocados por área) e sua base de escopo são atualizadas frequentemente pelas equipes de TVD.

16 A estimativa de custos do projeto é atualizada frequentemente para refletir as atualizações de custos das equipes de TVD.

17 A colocalização é fortemente aconselhada, pelo menos quando as equipes foram recém-formadas. Ela não precisa ser permanente, reuniões de equipes podem ser realizadas semanalmente ou mais frequentemente.

Fonte: adaptado de Ballard (2011). 
Conforme já salientado, até o momento as evidências de aplicações bem-sucedidas do TVD nos EUA provêm de empreendimentos voltados para a saúde e educação (apenas um) e pressupõem estágios avançados de integração e colaboração para utilização concomitante com o TVD (BALLARD; REISER, 2004; ZIMINA; BALLARD; PASQUIRE, 2012). Assim, o TVD contempla várias particularidades e pressupostos para sua aplicação literal. Vários desses pressupostos podem dificultar a replicação bemsucedida para outros países e contextos específicos. Portanto, configura-se a oportunidade de investigar se o TVD é aplicável em empreendimentos imobiliários no contexto nacional e como integrá-lo às práticas de desenvolvimento de produtos e, particularmente, à gestão do processo de projeto.

É importante ressaltar que a abordagem do TVD também é utilizada sob outras formas de contratação nos EUA além do IPD. O design-build (DB) (projetar-construir) e o construction management at risk (CMR) (gestão da construção em condições de risco) também são formas de contratação integradas que favorecem o uso do TVD (PISHDAD-BOZORGI; MOGHADDAM; KARASULU, 2014). No DB, diferentemente do que ocorre na abordagem IPD, o custo é estabelecido pelo cliente (ou proprietário) sem a participação dos projetistas ou executores. Preço e qualidade são levados em consideração no processo, e o proprietário não está envolvido diretamente nos processos de tomadas de decisão. Os projetistas e executores exercem o controle exclusivo sobre os processos de concepção/construção e tomada de decisão, bem como sobre a gestão de valor. O proprietário define os critérios de projeto sem qualquer participação do executor ou projetista, e estes decidem sobre "como" projetar, construir e gerenciar o processo, mantendo-se dentro das metas de custo. $\mathrm{O}$ processo de concepção/construção tem menor transparência para o proprietário. Essa abordagem do DB oferece uma solução mais apropriada de entrega de valor para os proprietários com menor grau de sofisticação gerencial, que não querem se envolver ativamente no projeto (PISHDAD-BOZORGI; MOGHADDAM; KARASULU, 2014).

No Brasil a abordagem mais frequente de entrega de produtos ainda é o Design-Bid-Build (projetarlicitar-construir) (DBB), forma de contratação na qual o custo é determinado a partir do projeto detalhado para execução. O DBB promove graus de integração e colaboração menores do que IPD, DB e CMR. Adicionalmente, no contexto nacional se ressalta a licitação competitiva para obras públicas, regida pela Lei $\mathrm{n}^{\circ} 8.666$, que permite a contratação de projeto e construção via três modalidades, melhor preço, melhor técnica e melhor preço e técnica, sendo esta última raramente utilizada no Brasil. Em geral, os profissionais da área alegam que a licitação competitiva raramente traz soluções com melhor valor agregado para a administração pública, uma vez que o preço não pode ser definido de forma apurada antes do estabelecimento do escopo (GRILO; MELHADO, 2004).

\section{Método de pesquisa}

Como estratégia de pesquisa adotou-se o estudo de caso exploratório. O estudo de caso é apropriado para responder a questões do tipo "por quê" e "como", e também quando o pesquisador tem pouca ou nenhuma possibilidade de controle dos eventos, ou ainda quando as circunstâncias gerais do fenômeno a ser estudado são contemporâneas, num contexto de situação real. Particularmente, o estudo de caso exploratório se destina ao desenvolvimento de teoria e à expansão do campo empírico do conhecimento (YIN, 2010). Adicionalmente, ele pode abrir caminho para novas pesquisas com vistas à generalização.

A unidade de análise de interesse da pesquisa é a gestão do processo de projeto de empreendimentos imobiliários no contexto nacional. Para tanto, as evidências foram coletadas em um escritório de desenvolvimento de projetos de arquitetura (EA) e em duas construtoras/incorporadoras (C/I 1 e $\mathrm{C} / \mathrm{I}$ 2). Os produtos específicos estudados nessas empresas relacionam-se ao contexto imobiliário na forma de unidades para venda.

As coletas de evidências foram feitas por meio de dois instrumentos: questionários e análise documental. Os questionários foram elaborados com base nos 17 princípios do TVD, e as entrevistas com o uso dos questionários foram feitas de forma semiestruturada (Quadro 2). Empregaram-se questões do tipo "aberta" ou "fechada-finalizada", sem uma ordem específica, porém formuladas de acordo com tópicos específicos (NAOM, 2007).

$\mathrm{Na}$ primeira etapa de coleta de evidências, o questionário 1 foi aplicado em dois agentes. $\mathrm{O}$ primeiro, uma construtora/incorporadora (C/I 1) de grande porte e atuação nacional há mais de 30 anos, posicionada entre as 10 maiores do Brasil (RANKING..., 2014). A C/I 1 desenvolve produtos imobiliários residenciais para diferentes faixas salariais, bem como produtos comerciais. Nessa etapa analisou-se um produto destinado ao Programa Minha Casa, Minha Vida (PMCMV) e foi entrevistada a gestora da área de 
desenvolvimento e projetos da C/I 1. O segundo agente foi um escritório de arquitetura (EA) com cerca de 10 funcionários que produz grande parte dos projetos para a $\mathrm{C} / \mathrm{I} 1$, cujo entrevistado foi o arquiteto-coordenador. Também foi consultado o manual de boas práticas para elaboração de projetos da C/I 1 .

$\mathrm{Na}$ segunda etapa de coleta de evidências novos dados foram coletados na mesma C/I 1, porém relacionados a outro produto de habitação, considerado um produto habitacional de média complexidade (PH 1), para uma faixa salarial a partir de R\$ 12.500,00 (aproximadamente, 17 salários mínimos em valores de 2014). Nessa etapa o entrevistado foi o gerente de produtos da empresa, ao qual se aplicaram os questionários $1 \mathrm{e}$ 2 em oportunidades diferentes.

$\mathrm{Na}$ última etapa da coleta de evidências, outra construtora/incorporadora foi analisada (C/I 2). Esta empresa atua há 27 anos no mercado privado, com grande foco em produtos imobiliários de alto padrão, e está entre as 100 maiores do Brasil (RANKING..., 2014). A C/I 2 desenvolve produtos comerciais e habitacionais, principalmente na região de São Paulo. Nessa etapa foi considerado um produto imobiliário habitacional de alto padrão e de alta complexidade (PH 2). Os questionários 1 e 2 foram respondidos por uma equipe mista, composta de gerente de projetos, coordenador comercial e gerente de orçamentos.

Sendo o TVD influenciado pelo IPD, que depende de níveis crescentes de colaboração entre as partes envolvidas no empreendimento para atingir seu pleno potencial, formulou-se a proposta de adoção do TVD desta pesquisa com base em três níveis evolutivos de colaboração (AMERICAN..., 2007). É interessante ressaltar que a evolução desses níveis de integração e colaboração depende da intensificação do uso de instrumentos contratuais (Quadro 3).

\section{Quadro 2 - Instrumentos utilizados para coletas de evidência}

\begin{tabular}{|c|l|}
\hline $\begin{array}{c}\text { Questionário 1 e } \\
\text { documentação }\end{array}$ & $\begin{array}{l}\text { O questionário 1 teve caráter exploratório. Destinou-se à identificação das } \\
\text { características gerais do processo de projeto no EA e na C/I 1. Além disso, o } \\
\text { manual de boas práticas do EA e um documento da C/I 1 contendo as fases de } \\
\text { desenvolvimento de projeto foram consultados. }\end{array}$ \\
\hline Questionário 2 & $\begin{array}{l}\text { O questionário 2 visou identificar oportunidades iniciais na C/I 1 e na C/I 2 para } \\
\text { adoção do TVD na gestão do processo de projeto. Para esse objetivo foram } \\
\text { considerados os princípios do TVD (Quadro 1). }\end{array}$ \\
\hline Questionário 3 & $\begin{array}{l}\text { Visou à identificação de mudanças necessárias na gestão do processo de projeto } \\
\text { da C/I 1 e da C/I 2 e ao desenvolvimento da proposta para adoção do TVD, } \\
\text { levando-se em consideração níveis evolutivos de integração e colaboração. }\end{array}$ \\
\hline
\end{tabular}

\section{Quadro 3 - Níveis de colaboração entre as partes envolvidas no empreendimento}

\begin{tabular}{|l|l|}
\hline Nível 1 - & $\begin{array}{l}\text { A colaboração é atingida em alguns aspectos sem a necessidade de contrato formal } \\
\text { entre os agentes envolvidos. } \\
\text { Típica } \\
\text { Características-chave: não necessita de contrato para alcançar alguns níveis de } \\
\text { colaboração; existem compartilhamento limitado de riscos e política de open-book } \\
\text { (compartilhamento de informações, inclusive financeiras). }\end{array}$ \\
\hline Nível 2 - & $\begin{array}{l}\text { Utilização de alguns tipos de contratos para se atingirem maiores níveis de } \\
\text { colaboração, como contratos de incentivo. } \\
\text { Adquirida } \\
\text { Características-chave: maior colaboração entre os agentes envolvidos, desde o início, } \\
\text { incentivos que buscam aumento da produtividade, envolvimento do cliente ou usuário } \\
\text { de forma mais ativa, maior comprometimento dos agentes nas tomadas de decisão. }\end{array}$ \\
\hline Nível 3 - & $\begin{array}{l}\text { Existência de contrato multipartes (LICHTIG, 2006) que envolvem os agentes em um } \\
\text { instrumento contratual único para se atingirem níveis mais abrangentes de } \\
\text { Requerida } \\
\text { calaboração. } \\
\text { empreiteiros principais) assinam um contrato único (multipartes) que exige } \\
\text { colaboração, compartilhamento de riscos e margens, tomadas de decisão de forma } \\
\text { conjunta entre os agentes e utilização de colocalização para desenvolvimento do } \\
\text { projeto. }\end{array}$ \\
\hline
\end{tabular}

Fonte: adaptado de American Institut of Architects (2007). 
Assim, além dos questionários 1 e 2, um terceiro questionário foi elaborado e aplicado nas entrevistas com agentes da C/I 1 e C/I 2 com o objetivo de compreender os níveis de evolução de colaboração necessários para a implantação dos 17 princípios do TVD. Para a proposta da pesquisa foram estipulados três níveis: 1 - curto, 2 - médio e 3 - longo prazo. Esses três níveis de colaboração norteiam a adoção da proposta do TVD desta pesquisa de forma gradual e contemplam os níveis de formalização contratual necessários.

Uma vez que os 17 princípios do TVD ainda são pouco conhecidos pelos entrevistados, ou mesmo pouco compreendidos, elaboraram-se descrições mais completas na forma de recomendações, as quais balizaram a formulação das questões dos questionários. Essas recomendações e as respectivas conexões com os princípios do TVD são apresentadas a seguir:

(d) estabelecimento do custo-meta de projeto logo no início de seu desenvolvimento, de forma que somente a $\mathrm{C} / \mathrm{I}$ pode alterá-lo: visa estabelecer o custo como parâmetro de projeto logo no início, para que possa se constituir num desafio capaz de induzir a criatividade e a inovação (Princípio 9);

(e) envolvimento dos participantes no empreendimento desde o início do projeto (fornecedores principais, projetistas e usuários finais): busca promover colaboração verdadeira desde as fases iniciais de concepção do empreendimento (Princípios 1, 2, 3, 4, 5, 6 e 10);

(f) estimativa de custos de forma contínua: incentivar que as equipes verifiquem continuamente se os custos não estão sendo excedidos e que trabalhem sempre nesse sentido. A cada etapa essas estimativas são atualizadas e compartilhadas entre todos os envolvidos, com reuniões frequentes das equipes para discutir soluções baseadas não só nos custos mas também em requisitos de qualidade e desempenho (Princípios 10, 11, 15 e 16);

(g) contratos de incentivo entre a $\mathrm{C} / \mathrm{I}$ e os parceiros envolvidos, incluindo compartilhamento de riscos e margens: visa estabelecer relações de confiança (trust) entre os agentes envolvidos e incentiva-os a buscar melhores soluções que desafiem os patamares atuais de custo, sempre salvaguardando requisitos de desempenho e qualidade (Princípio 8);

(h) treinamento em lean e em TVD antes do início do empreendimento: é necessário que os agentes envolvidos comecem a ter contato com essas filosofias e princípios para que possam ser assimilados e implantados. (Este aspecto não está relacionado diretamente com os 17 princípios, porém é um pressuposto relevante para facilitar a implantação);

(i) colocalização (colocation) das equipes: relaciona-se ao conceito de big room, qual seja, a utilização de um ambiente físico compartilhado para desenvolvimento do projeto entre as equipes multidisciplinares. A estratégia da colocalização potencializa a colaboração e a troca de informações e ideias. Não necessariamente todo o processo de projeto precisa ser desenvolvido sob a forma de colocalização, porém é interessante que seja acordada uma frequência preestabelecida para seu uso (Princípio 17);

(j) identificação do que é valor para o cliente ou usuário final: esta recomendação pode ser implantada por meio da avaliação do último empreendimento semelhante já entregue, utilizando-se ferramentas lean tais como TVD, IPD e Sistema Last Planner (BALLARD, 2000) (Princípio 8);

(k) feedback contínuo do usuário final: ao final de cada empreendimento também deve ser feita uma avaliação para identificar se as percepções de valor desejado dos usuários foram satisfeitas ou se elas mudaram (Princípios 8 e 10);

(1) consideração do ponto de vista do usuário final como peça-chave do processo, norteando todas as etapas de desenvolvimento do projeto: na finalização de cada etapa, ou a cada grande mudança nas soluções de projeto, deve ser feita uma avaliação a partir da perspectiva do usuário final com o objetivo de se identificar se o produto final ainda se encontra dentro de suas perspectivas de valor desejado (Princípios 6 e 8);

(m) entendimento completo de todos os membros da equipe com relação ao empreendimento e do que representa valor para as partes envolvidas: esta recomendação prioriza a comunicação entre os envolvidos, que ocorre quando há verdadeira colaboração (Princípios 7 e 14);

(n) o estudo de viabilidade envolve todos os agentes que participarão do empreendimento: a participação de todos os agentes propicia que as metas de custos e possibilidades de intervenção fiquem mais claras para as equipes multidisciplinares (Princípios 1, 2, 3, 4 e 5);

(o) a motivação de participação de todos os envolvidos deve estar alinhada com os objetivos do empreendimento: esta recomendação pode ser alcançada por meio de contratos de incentivo, de forma a compartilhar os ganhos financeiros entre os envolvidos, por exemplo, com vistas a estabelecer bônus no caso de redução de custos sem redução de escopo. Esse aspecto pode incentivar a busca de novas soluções de projeto 
sem perder de vista a qualidade final do produto e a percepção de valor do usuário final (Princípio 8);

(p) seleção das equipes baseada em valor: os agentes que participarão do empreendimento devem ser selecionados não somente com base em preço mas também em quesitos de valor que poderão oferecer. São aspectos desejados experiência prévia em trabalhos colaborativos e demonstração de foco no usuário final (Princípios 7 e 8$)$;

(q) transparência de informações entre construtora e equipes com relação aos planos, custos e gastos para o empreendimento: a transparência entre os participantes facilita obter um trabalho integrado e colaborativo. Situações típicas são evitadas, nas quais o agente que detém o maior poder de negociação obtém vantagem financeira sobre os demais (Princípios 6, 7, 8 e 14);

(r) uso de ferramentas: emprego de BIM como sistema informatizado para integração do projeto, mock-ups (modelo em escala do empreendimento), entre outras, para facilitar a avaliação do empreendimento e seu desenvolvimento (Princípio 12);

(s) metas flexíveis: as metas a serem atingidas devem ser estabelecidas, porém certa flexibilidade é desejável, desde que as metas orçamentárias não ultrapassem os valores previamente estabelecidos. Para isso, a inovação e a busca por novas soluções devem ser incentivadas (Princípios 9 e 13);

(t) as equipes apresentam suas percepções de risco, e a construtora também se compromete a assumir parte delas: dessa forma as partes envolvidas percebem um ambiente de compartilhamento transparente de informações. Ao mesmo tempo, são encorajadas a buscar soluções diferenciadas para o empreendimento (Princípio 8); e

(u) todos os envolvidos trabalham nas mesmas condições: torna-se importante que as equipes multidisciplinares trabalhem envolvidas com a gestão do processo de projeto, desde a concepção até a finalização (Princípio 8).

\section{Análise das evidências coletadas}

A seguir discutem-se as evidências coletadas no EA e nas C/I 1 e C/I 2, que nortearam a proposta de adoção do TVD desta pesquisa.

\section{Evidências coletadas no EA e na C/I 1 - PMCMV}

As evidências coletadas nas entrevistas mostraram que, de modo geral, boa parte dos princípios do TVD não é aplicada. Apurou-se que alguns desses princípios são aplicados apenas de maneira parcial, que ainda necessitam de melhorias com o intuito de que os benefícios do TVD sejam plenamente alcançados. Além disso, nas entrevistas realizadas foi comum ouvir dos entrevistados que alguns princípios já eram utilizados na gestão do processo de projeto de suas respectivas empresas. Assim, foram propostas escalas de enquadramento da utilização dos 17 princípios, a saber:

(a) não aplicado;

(b) aplicado não sistematicamente ou apenas parcialmente;

(c) aplicado, porém são necessárias mudanças; e

(d) aplicado de maneira sistemática (Figura 2).

No caso deste produto (PMCMV) identificou-se um ambiente de pouca colaboração e integração, de certa forma adverso aos conceitos preconizados pelo TVD. Por esse motivo, um segundo tipo de produto na própria $\mathrm{C} / \mathrm{I} 1 \mathrm{com}$ características mais explícitas de integração e colaboração foi escolhido.

Figura 2 - Síntese da aplicação dos 17 princípios do TVD (C/I 1 - PMCMV)

\begin{tabular}{|c|c|c|c|c|c|c|c|c|c|c|c|c|c|c|c|c|c|}
\hline & \multicolumn{17}{|c|}{ Princípios do TVD } \\
\hline & 1 & 2 & 3 & 4 & 5 & 6 & 7 & 8 & 9 & 10 & 11 & 12 & 13 & 14 & 15 & 16 & 17 \\
\hline PMCMV & & & & & & & & & & & & & & & & & \\
\hline
\end{tabular}

Legenda:

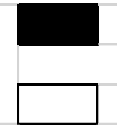

Não aplicado

Aplicado, mas mudanças são necessárias

Aplicação não sistemática ou parcial

Aplicado sistematicamente

Nota: explicitação dos 17 princípios do TVD no Quadro 1.

138 Oliva, C. A.; Granja, A. D. 


\section{Evidências coletadas na C/I 1 - PH 1}

$\mathrm{Na}$ C/I 1 o processo de projeto igualmente ocorre para toda a sua família de produtos, mesmo se considerando faixas salariais diferentes. As evidências coletadas com relação à observância ou não dos 17 princípios no desenvolvimento do $\mathrm{PH} 1$ estão representadas na Figura 3.

Seguem algumas reflexões a partir das evidências e observações adicionais coletadas na C/I 1 (PH 1) com vistas a proporcionar maiores níveis de integração e colaboração:

(a) as equipes de projeto de arquitetura deveriam participar da fase de viabilidade, uma vez que na situação atual participam apenas a partir da fase de estudo preliminar;

(b) as equipes de projetos complementares também deveriam participar em etapas mais precoces do processo de projeto. No caso analisado, elas participam em conjunto a partir da fase de estudo preliminar até o projeto executivo;

(c) existe envolvimento de alguns fornecedores durante o processo de projeto para assegurar retroalimentação ao projeto e fornecer consultorias específicas;

(d) parâmetros mínimos de projeto são definidos na reunião de definição de produto com as equipes de projeto, por meio da técnica de brainstorming;

(e) o usuário final participa durante a fase de execução do empreendimento com visitas préagendadas pela C/I 1. Porém, o mecanismo de retroalimentação para desenvolvimento de novos produtos se dá apenas na pós-entrega, por meio de uso de técnicas como a avaliação pós-ocupação (APO);

(f) existe certa flexibilidade nas metas estabelecidas, e novas soluções são sempre incentivadas por parte da C/I 1. Além disso, as metas relativas ao escopo e custos são alocadas para todas as equipes de projeto;

(g) existe uma estimativa de custos preestabelecida pela C/I 1. Os valores estimados de elementos representativos da edificação, tais como arquitetura, estruturas, sistemas hidráulicos, sanitários e elétricos, são apresentados para as equipes. As estimativas se tornam metas para guiar o desenvolvimento do projeto e, caso sejam ultrapassadas, são atualizadas e a área respectiva é responsável por promover alterações no projeto para adequá-lo;

(h) antes do lançamento do empreendimento, elabora-se uma previsão de orçamento, sujeita à revisão e detalhamento apenas na conclusão do projeto executivo;

(i) as reuniões de projeto não ocorrem com frequência preestabelecida. As reuniões com todos os envolvidos visam mais à compatibilização dos projetos do que à discussão de novas soluções e estimativa de custos das equipes para as soluções apresentadas;

(j) os projetistas nem sempre têm entendimento pleno das especificações, necessidades e o que representa valor para o empreendimento, clientes ou usuários finais; $\mathrm{e}$

(k) apesar de os usuários finais desses produtos terem maior discernimento sobre itens representativos de valor e fazerem comparação entre produtos concorrentes, essas informações são subutilizadas na retroalimentação do processo de projeto.

\section{Evidências coletadas na C/I 2 - PH 2}

As evidências coletadas com relação à observância ou não dos 17 princípios no desenvolvimento do PH 2 na C/I 2 estão representadas na Figura 4.

Figura 3 - Síntese da aplicação dos 17 princípios do TVD (C/I 1 - PH1)

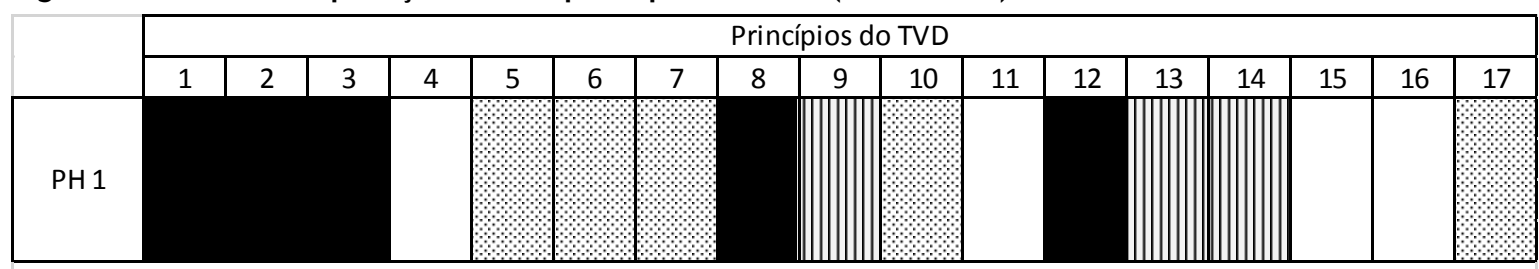

Legenda:

\begin{tabular}{ll}
\hline Não aplicado & Aplicado, mas mudanças são necessárias \\
\hline & Aplicação não sistemática ou parcial \\
\hline
\end{tabular}

Nota: explicitação dos 17 princípios do TVD no Quadro 1. 
Figura 4 - Síntese da aplicação dos 17 princípios do TVD (C/I 2 - PH2)

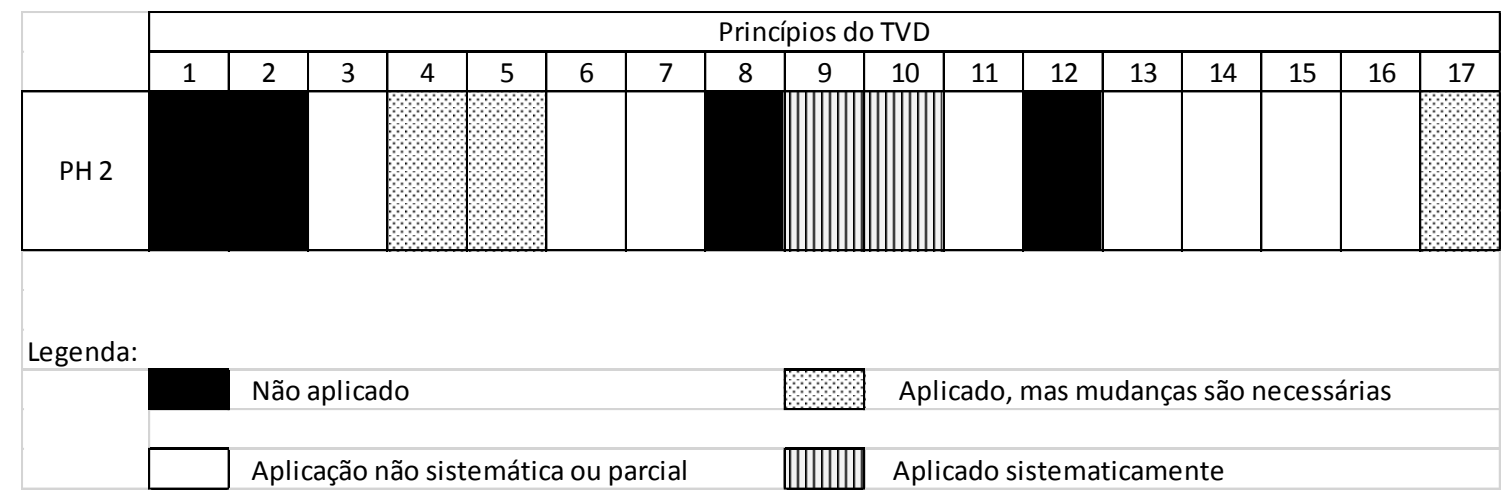

Nota: explicitação dos 17 princípios do TVD no Quadro 1.

A seguir, destacam-se aspectos e evidências complementares, que podem representar melhorias para se atingirem níveis mais elevados de colaboração e integração entre os agentes:

(a) a retroalimentação do usuário final é obtida por meio de pesquisas de APO e também de entrevista na etapa de pré-venda, que norteia futuros lançamentos;

(b) as etapas de projeto ocorrem de forma similar às da C/I 1, ou seja, busca pelo terreno, estudo preliminar, anteprojeto, pré-executivo e executivo, e, por fim, liberação para a execução da obra;

(c) o estudo de viabilidade não é capaz de produzir um orçamento detalhado. Neste estudo, o escopo é definido, e a área de orçamentos aprofunda os estudos para que ele seja concluído até o lançamento do empreendimento;

(d) as equipes nem sempre possuem entendimento completo das especificações, necessidades e o que é valor para o empreendimento, cliente ou usuário final. A empresa desenvolve documentos com diretrizes de projeto e escopo das entregas para cada especialidade projetual. Parcerias são preferidas com projetistas que já possuem conhecimento das diretrizes da C/I 2;

(e) as metas de custo para o empreendimento não são alocadas para as equipes de projeto; apenas as metas de escopo o são;

(f) a C/I 2 possui certa flexibilidade nas metas de custos, e estas podem ser alteradas pela empresa, desde que justificadas e aprovadas pela diretoria;

(g) a busca por novas soluções é encorajada e incentivada pela empresa;

(h) a empresa possui estimativa de custos para o empreendimento, porém eles não são compartilhados com os projetistas. Apenas os parâmetros de escopo definidos pela C/I 2 são compartilhados; (i) os custos são atualizados pela equipe de orçamentos ao longo do desenvolvimento do projeto; e

(j) os fornecedores principais participam durante o processo de projeto por meio de atividade consultiva. Mesmo assim, essa participação deveria ser intensificada.

\section{Síntese comparativa das evidências coletadas no EA, C/I 1 (PMCMV e PH 1) e $\mathrm{C} / \mathrm{I} 2$ (PH 2)}

As evidências coletadas no EA, C/I 1 (PMCMV e $\mathrm{PH} 1$ ) e C/I 2 ( $\mathrm{PH} 2$ ) propiciaram uma síntese sobre a ocorrência ou não dos 17 princípios do TVD no processo de projeto dos produtos analisados. A Figura 5 possibilita comparações sobre a aplicação dos 17 princípios do TVD na $\mathrm{C} / \mathrm{I}$ 1 e na C/I 2. Uma vez que as evidências da C/I 1 foram coletadas a partir de dois produtos (PMCMV e PH1) e que sua gestão do processo de projeto é padronizada, verifica-se que para uma possível adoção do TVD intervenções diferenciadas nesse processo são necessárias, conforme o produto de interesse. Como na C/I 2 a gestão do processo de projeto é menos estruturada do que na C/I 1, presume-se que a adoção do TVD apresente maiores barreiras.

\section{Relação dos 17 princípios do TVD com níveis requeridos de integração e colaboração}

Os resultados do questionário 3 aplicado na C/I 1 e na C/I 2 são exibidos no Quadro 4. Nele são explicitados os horizontes requeridos para a incorporação gradual dos 17 princípios do TVD na opinião dos entrevistados nas C/I 1 e C/I 2. Esses horizontes, de curto, médio e longo prazos, nortearam a elaboração da proposta de adoção do TVD, que será apresentada mais à frente. 
Dado o desconhecimento do TVD e mesmo do IPD pelos entrevistados, eles tiveram dificuldades em relacionar os níveis de formalização contratual requeridos para a implantação dos princípios do TVD. Assim, estabeleceu-se uma conexão dos níveis curto, médio e longo prazo, objeto das entrevistas, com os três níveis de formalização contratual necessários a partir de AIA (AMERICAN..., 2007), quais sejam: nível 1 típica; nível 2 - adquirida; e nível 3 - requerida (Quadro 3). Em outras palavras, princípios alocados no nível de curto prazo exigem menor ou nenhuma formalização contratual e no médio e longo, estruturas contratuais mais explícitas. Ainda assim, algumas alocações de princípios a partir dos entrevistados foram modificadas na proposta de adoção do TVD apresentada mais à frente. Por exemplo, em relação ao princípio 7 , evidenciado como de longo prazo pelas empresas, alterou-se seu enquadramento na proposta apresentada mais à frente para o nível 1 , ou seja, o princípio 7 expressa o entendimento comum dos valores do empreendimento pelas partes interessadas, o que não necessariamente exige um contrato formal para ser implantado. Portanto, na proposta apresentada à frente, o princípio 7 foi alocado no nível 1 - típica.

Figura 5 - Síntese comparativa dos dados coletados - 17 princípios do TVD

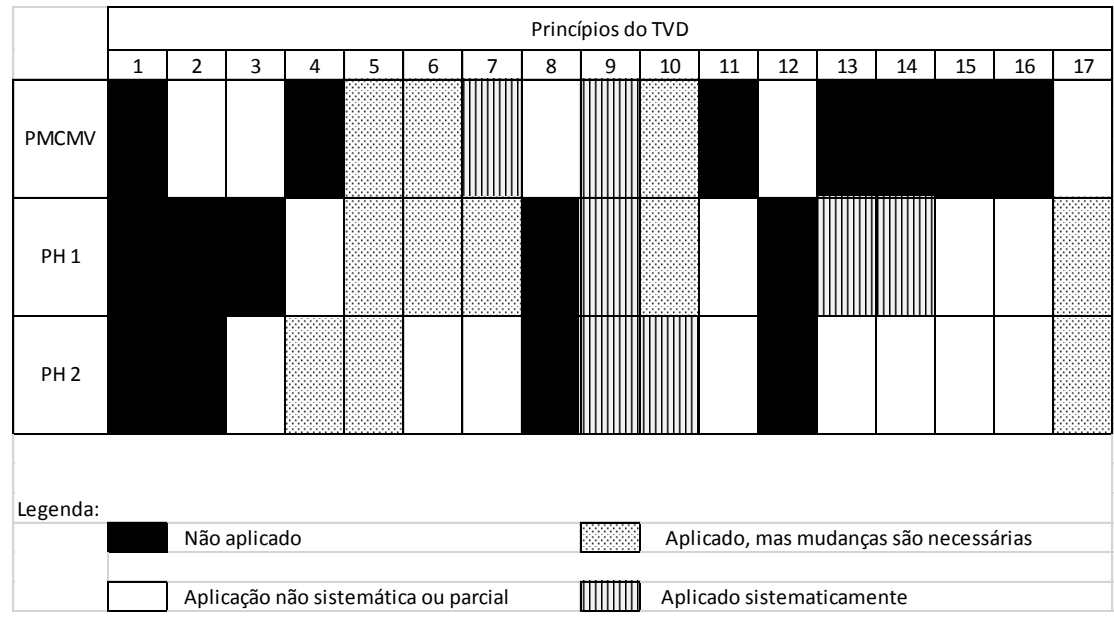

Nota: explicitação dos 17 princípios do TVD no Quadro 1.

\section{Quadro 4 - Proposta de alocação dos 17 princípios do TVD conforme os níveis de formalização} contratual necessários (AMERICAN..., 2007)

\begin{tabular}{|c|c|c|}
\hline Princípio & C/I 1 & C/I 2 \\
\hline 1 & $\mathrm{~L}$ & $\mathrm{M}$ \\
\hline 2 & $\mathrm{~L}$ & $\mathrm{M}$ \\
\hline 3 & $\mathrm{~L}$ & $\mathrm{M}$ \\
\hline 4 & $\mathrm{~L}$ & $\mathrm{M}$ \\
\hline 5 & $\mathrm{M}$ & $\mathrm{M}$ \\
\hline 6 & $\mathrm{C}$ & $\mathrm{C}$ \\
\hline 7 & $\mathrm{~L}$ & $\mathrm{~L}$ \\
\hline 8 & $\mathrm{~L}$ & $\mathrm{~L}$ \\
\hline 9 & $\mathrm{C}$ & $\mathrm{C}$ \\
\hline 10 & $\mathrm{C}$ & $\mathrm{C}$ \\
\hline 11 & $\mathrm{M}$ & $\mathrm{L}$ \\
\hline 12 & $\mathrm{~L}$ & $\mathrm{~L}$ \\
\hline 13 & $\mathrm{M}$ & $\mathrm{C}$ \\
\hline 14 & $\mathrm{M}$ & $\mathrm{C}$ \\
\hline 15 & $\mathrm{M}$ & $\mathrm{L}$ \\
\hline 16 & $\mathrm{M}$ & $\mathrm{L}$ \\
\hline 17 & $\mathrm{~L}$ & $\mathrm{~L}$ \\
\hline
\end{tabular}

Nota: explicitação dos 17 princípios do TVD no Quadro 1.

Legenda: $C$ - curto prazo; $M$ - médio prazo; e $L$ - longo prazo. 
Optou-se ainda por rotular dois catalisadores, que têm como objetivo acelerar o processo de integração entre os envolvidos (AMERICAN..., 2007), os quais não necessariamente se enquadram como princípios. Nessa classificação optou-se por incluir o sistema Last Planner (princípio 12 do Quadro 1) e o BIM (Building Information Modeling), uma vez que nem todas as empresas adotam esses sistemas e porque eles não são enquadrados como pré-requisitos, e sim catalisadores para a implantação do TVD. Os catalisadores não são obrigatórios - seria possível adotar o TVD sem eles -, no entanto são elementos importantes para se atingirem níveis mais sofisticados de colaboração. Eles podem ser considerados em qualquer um dos três níveis de colaboração propostos para o TVD.

Por fim, é importante ressaltar que em um momento anterior à adoção do TVD é interessante que a empresa e os envolvidos no processo tenham um período de aprendizado sobre seus conceitos, necessário para a implantação de qualquer mudança organizacional. Esse aprendizado visa ao entendimento sobre o porquê das mudanças propostas no processo e ao auxílio na mudança de paradigmas organizacionais para uma integração do TVD de forma mais eficiente.

\section{Proposta de adoção do tvd na gestão do processo de projeto de empreendimentos imobiliários}

Tendo em vista as evidências coletadas no EA, C/I 1 (PMCMV e PH1) e C/I 2 (PH 2), elaborou-se a proposta de adoção do TVD na gestão do processo de projeto de empreendimentos imobiliários levando-se em consideração níveis de colaboração evolutivos para sua implantação gradual, representado na Figura 6, utilizando o BIM e o sistema Last Planner como catalisadores do processo (Figura 6).

A seguir, a proposta foi avaliada nas $\mathrm{C} / \mathrm{I} 1$ (PMCMV e PH 1) e C/I 2 (PH2), utilizando-se da mesma classificação anterior, a saber:

(a) não aplicado;

(b) aplicado não sistematicamente ou apenas parcialmente;

(c) aplicado, porém são necessárias mudanças; e

(d) aplicado de maneira sistemática, apurando-se os resultados encontrados durante as entrevistas.

Observando-se a Figura 7, com relação ao produto PMCMV, pode-se sugerir que a C/I 1 encontra-se em um nível básico de colaboração, com dois dos três princípios do nível básico sendo aplicados de forma sistemática (princípios 7 e 9). Porém, a maioria dos princípios não é aplicada, necessitando-se de práticas colaborativas mais evoluídas para se atingirem os próximos níveis. No caso de produtos para o PMCMV, a empresa não faz utilização de Last Planner ou BIM.

A seguir, na Figura 8, encontra-se a validação da $\mathrm{C} / \mathrm{I} 1$ para o produto $\mathrm{PH} 1$. Verifica-se que alguns princípios são aplicados ainda que de forma não sistemática, ou necessitando de mudanças para melhorar sua efetividade, sendo possível inferir que a C/I 1 atualmente se encontra entre os níveis 1 e 2 de colaboração, além de já utilizar o sistema Last Planner em alguns empreendimentos. Não obstante, a utilização do BIM ainda é incipiente. A partir dos pontos ainda não aplicados, a empresa poderá elaborar um plano de mudanças.

Figura 6 - Proposta dos 17 princípios do TVD em níveis crescentes de colaboração. - o princípio 12 (sistema Last Planner) e o BIM foram classificados como catalisadores

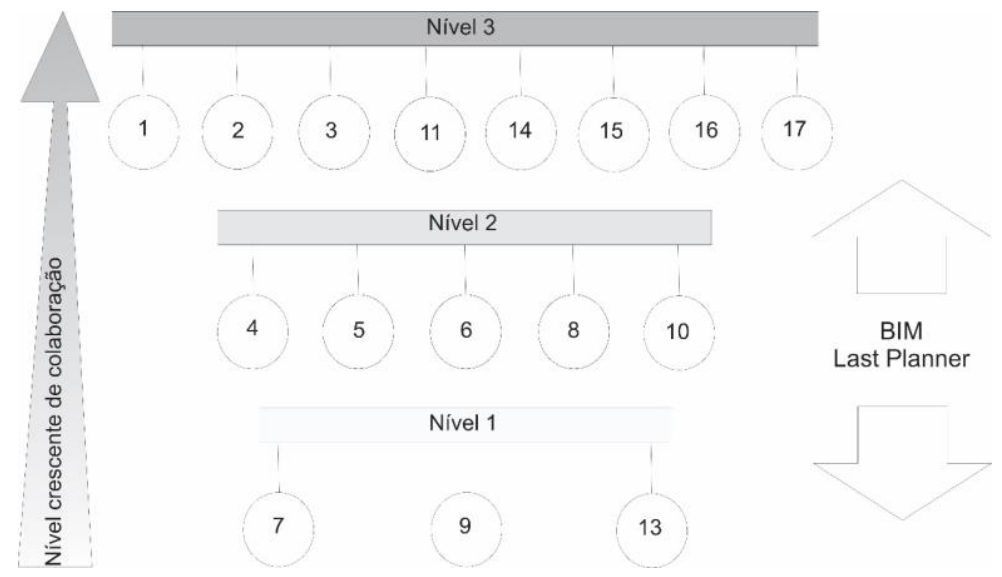

Nota: explicitação dos 17 princípios do TVD no Quadro 1. 
Figura 7 - Análise dos níveis de colaboração dos princípios do TVD na C/I 1 (PMCMV)

Construtora/Incorporadora 1/ EA - PMCMV

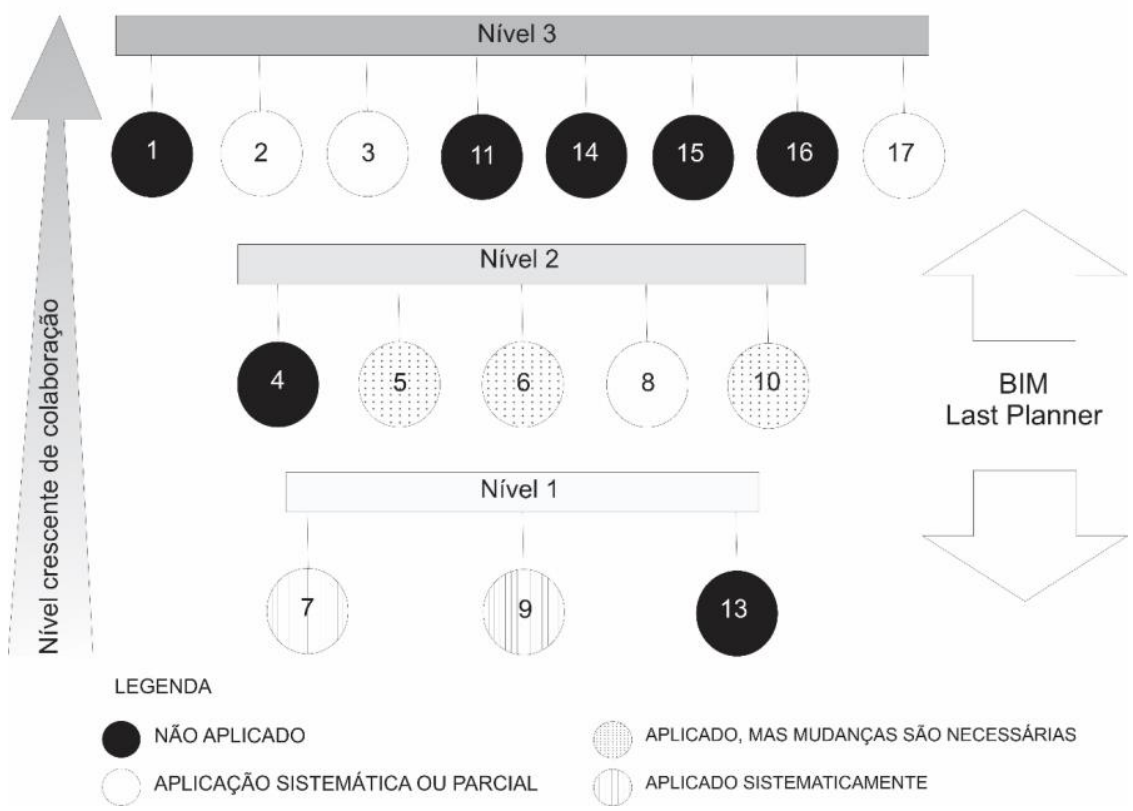

Nota: explicitação dos 17 princípios do TVD no Quadro 1.

Figura 8 - Análise dos níveis de colaboração dos princípios do TVD na C/I 1 (PH 1)

Construtora/Incorporadora 1 - PH1

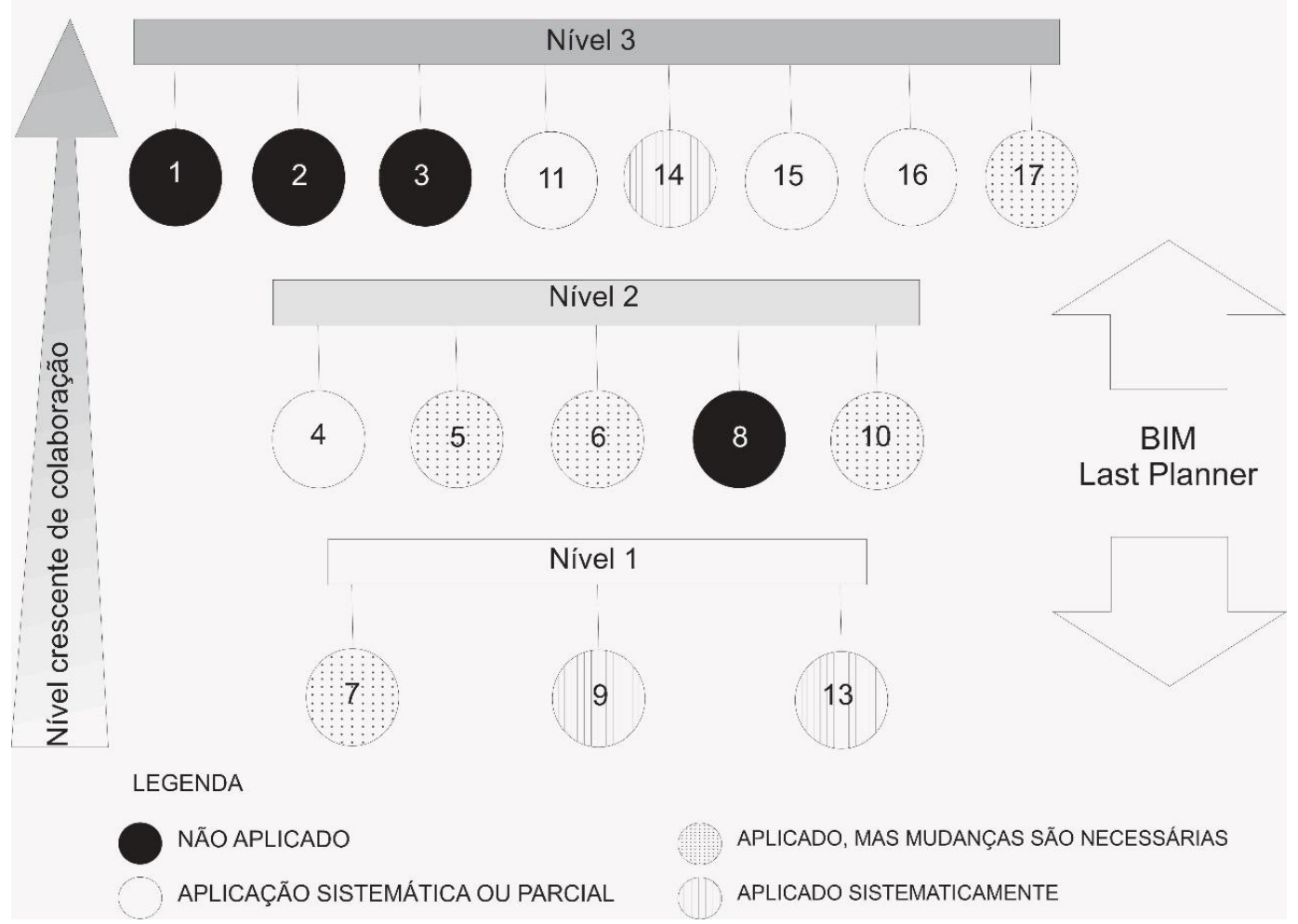

Nota: explicitação dos 17 princípios do TVD no Quadro 1. 
Conforme citado anteriormente, os itens no nível 1 não necessitam de formalização contratual. $\mathrm{O}$ princípio 7 , por exemplo, ainda não é aplicado de forma sistemática na $\mathrm{C} / \mathrm{I} 1$ e foi indicado pelos entrevistados como de longo prazo para adequação (Quadro 4). Esse princípio é chave para a integração da equipe, pois se relaciona ao entendimento do empreendimento e da percepção de valor das partes interessadas. Isso ocorre porque ainda existe certa dificuldade das construtoras em transmitir aos envolvidos - em especial aos projetistas - os objetivos do empreendimento como um todo, bem como em cada parte entender o que é valor para as demais. No entanto, não há necessidade de formalização contratual para sua adoção prática, e assim foi proposto que esse princípio fosse incorporado ao nível 1 (Figura 8).

A Figura 9 replica a mesma lógica de diagnóstico de ocorrência dos princípios do TVD na C/I 2. É possível se inferir que, em comparação com a $\mathrm{C} / \mathrm{I}$ 1, a C/I 2 possui práticas ainda mais prematuras de colaboração. De forma geral, é possível se inferir a partir evidências que o processo de projeto da C/I 2 é ainda predominantemente tradicional, ou seja, sequencial e departamentalizado, além de pouco estruturado.

A C/I 2 ainda possui diversos princípios aplicados de forma parcial ou não sistemática, ou ainda de forma que necessite de mudanças para que seja possível usufruir de todos os benefícios de uma adoção plena do TVD. Apenas os princípios 9 e 10 são aplicados de forma sistemática, indicando que alterações no processo de desenvolvimento de produtos ainda são necessárias e precisam de ampla discussão, iniciando-se pela alta gerência da empresa, passando para toda a sua estrutura. A adoção do TVD é possível, porém de forma muito gradual, e pode iniciar com workshops para primeiros contatos com essa nova abordagem gerencial.

\section{Discussão e considerações finais}

Algumas inferências sobre a adoção do TVD no processo de projeto de empreendimentos imobiliários puderam ser formuladas. No caso de empreendimentos voltados para o PMCMV da C/I 1, a baixa complexidade do produto, as baixas expectativas dos usuários, os parâmetros mínimos exigidos pelo programa e as leis que regem o programa sugerem uma integração do TVD em um estágio inicial. Não obstante, mantêm-se as prerrogativas de melhorar o produto final entregue, salvaguardando-se as expectativas financeiras esperadas pelas partes interessadas. No contexto do PMCMV, o nível 1 (Figura 7) não exige mudanças contratuais em relação às práticas tradicionais e é de aplicação mais simples.

Outro ponto a ser destacado está relacionado à complexidade. Quanto maior a complexidade do produto, maiores os benefícios de uma integração do TVD no processo de projeto. Nos EUA os casos bem-sucedidos de aplicação se deram até o momento em empreendimentos voltados para a construção de hospitais - um produto de alta complexidade. Além disso, conhecimentos prévios pelas empresas participantes sobre modelos gerenciais diferenciados, tais como o IPD, facilitariam a aplicação. De acordo com as evidências desta pesquisa, a adoção dos conceitos e princípios do TVD no Brasil exigiria transformações mais abrangentes na gestão tradicional do processo de projeto, na cultura da empresa e em suas práticas gerenciais. Como em todo processo de inovação gerencial, as mudanças mais abrangentes do TVD concentram-se nos níveis de médio e longo prazos e exigem comprometimento dos envolvidos.

As restrições orçamentárias frequentes em empreendimentos do setor também precisam ser assimiladas de forma diferente. De maneira geral, a determinação do custo de um empreendimento é consequência do projeto concluído. Dentro da lógica do CM/TVD, os custos necessitam ser assimilados como parâmetro de entrada no projeto, no papel de indutores de criatividade e inovação, uma vez que são estipulados como metas a serem atingidas já a partir de etapas precoces de concepção do produto.

Outra restrição presente frequentemente em empreendimentos de unidades destinadas à venda diz respeito ao tempo para o lançamento dos produtos. As evidências coletadas nas empresas pesquisadas caracterizaram, com algumas particularidades, um processo tradicional, departamentalizado e sequencial para desenvolvimento dos produtos, com iterações redundantes e desperdícios no fluxo de informações. A combinação do TVD associado ao IPD vislumbra ciclos de práticas integradas e colaborativas, tornando o processo de desenvolvimento do produto mais eficiente, apesar de muitas vezes encontrar resistência em sua aplicação, pois o tempo para seu desenvolvimento pode se tornar mais longo, devido ao ciclo mais intenso de discussões projetuais. No entanto, a necessidade de maior dedicação às fases iniciais de desenvolvimento e planejamento pode acarretar em efeitos positivos na própria execução do empreendimento, uma vez que desperdícios de tempo com retrabalhos podem ser minimizados e a qualidade do produto entregue pode ser otimizada. 
Figura 9 - Análise dos níveis de colaboração dos princípios do TVD na C/I 2 (PH 2)

Construtora/Incorporadora 2 - $\mathrm{PH} 2$

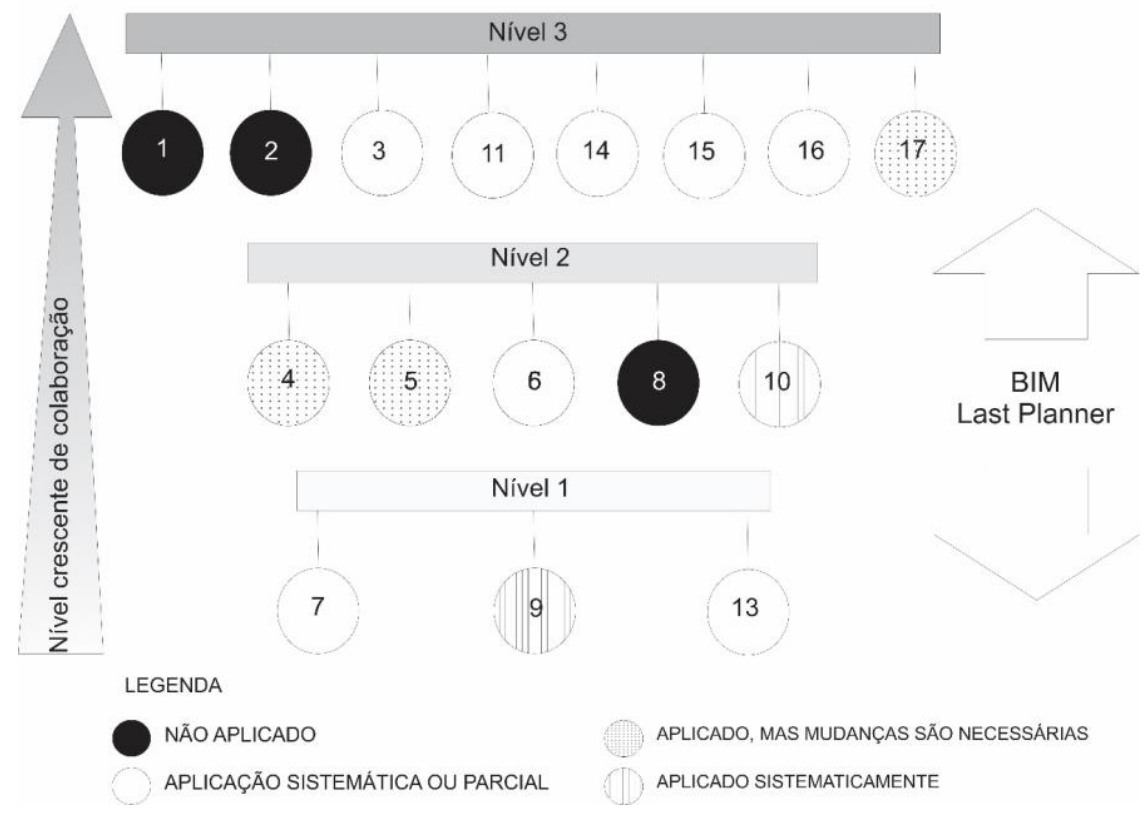

Nota: explicitação dos 17 princípios do TVD no Quadro 1.

Outro aspecto central do TVD é a colaboração. O envolvimento de todos os agentes desde o início do processo de desenvolvimento de produto e do projeto é importante para que seja possível uma visão sistêmica do empreendimento, bem como análises de como as partes exercem influência nos custos do produto. Algumas ferramentas podem auxiliar as partes interessadas no empreendimento a atingir níveis mais sofisticados de colaboração. Os contratos relacionais (LICHTIG, 2006) são, por exemplo, importantes indutores de colaboração no sentido de auxiliar a alinhar os objetivos de todos os envolvidos com os objetivos do empreendimento, bem como incentivar a colaboração entre os agentes e o empenho dos envolvidos na busca de boas soluções que estejam dentro das metas de custos, escopo e cronograma estabelecidos.

O cliente ou usuário final, representado por suas percepções de valor em relação ao empreendimento, deve ser peça-chave na gestão do processo de projeto, juntamente com o custo, que se configura como uma das principais restrições no desenvolvimento de qualquer produto. Dessa maneira, a empresa pode alocar esforços direcionados a elementos e funções do produto que o usuário considera como valor e está disposto a pagar por eles, em vez de alocar recursos em outros itens menos valorados (RUIZ; GRANJA; KOWALTOWSKI, 2014). Esses parâmetros também balizam o processo de decisão entre um produto e outro, e muitas vezes o cliente ou usuário final pode estar disposto a pagar mais para ter benefícios a partir de suas próprias percepções de valor. Assim, as soluções de projeto devem ser avaliadas a cada etapa, levando-se em consideração as análises de trade-off entre entrega de valor e os custos envolvidos.

Por fim, além dos usuários, os principais fornecedores e prestadores de serviços também são peças-chave na adoção do TVD. Usualmente eles participam somente a partir da etapa de execução do empreendimento. Dessa forma, a possibilidade de interações proativas para o empreendimento é reduzida. Assim, o envolvimento desses agentes desde as etapas iniciais de concepção deveria ser encorajado para a obtenção de benefícios adicionais, tais como a discussão de parâmetros de construtibilidade a partir da expertise em suas áreas técnicas de atuação.

Como contribuição principal do presente artigo, a proposta para adoção do TVD na gestão do processo de projeto em empreendimentos imobiliários representa os primeiros passos para a adoção de uma nova abordagem gerencial, na qual, primeiramente, um diagnóstico sobre a situação corrente da gestão do processo na empresa é necessário. De posse desse diagnóstico, a empresa pode direcionar esforços para incorporar os demais princípios, bem como estabelecer estratégias para aprimorar os níveis de integração e colaboração na gestão do processo de projeto de seus produtos em direção a aplicações de pleno potencial da proposta. 
Limitações e barreiras importantes para a adoção do TVD foram identificadas a partir da pesquisa, apresentadas a seguir:

(a) generalização da proposta: existem limitações para a generalização da proposta apresentada. Essa dificuldade se apresenta porque diferentes empresas se encontram em níveis diferentes de estágios de colaboração, elemento gênese do TVD, justificando-se a necessidade de estudos adicionais;

(b) particularidades do processo em si: conforme foi possível observar, apesar de o processo de projeto ocorrer de forma semelhante e em etapas parecidas nas empresas estudadas, ainda assim existiram distinções nos processos investigados. Por exemplo, a forma de contratação das equipes, a possibilidade de participação dos fornecedores durante a etapa de projeto e mesmo a forma de trabalho de cada equipe parecem ser fatores que podem indicar maior facilidade de integração do TVD; ou, do contrário, representar obstáculos para sua aplicação; e

(c) necessidades de mudanças organizacionais: de acordo com as necessidades de mudanças exigidas por toda inovação gerencial, este é um aspecto sensível para a implantação bem-sucedida do TVD. A adoção do TVD se tornará possível, ainda que somente nas etapas iniciais, se houver engajamento e esforços organizacionais em direção à mudança. Essa iniciativa deve ser endossada a partir do comprometimento da alta gerência da empresa. A empresa deve buscar e propor parcerias com equipes que entendam seus valores e também estejam dispostas a adotar tais mudanças. As empresas estudadas mostraram interesse no TVD, porém admitiram que as mudanças organizacionais necessárias são abrangentes e exigiriam médio e longo prazo para implantação.

A pesquisa também abriu oportunidades para trabalhos futuros. Sugere-se testar a proposta apresentada para outros produtos habitacionais ou mesmo para outros tipos de empreendimentos, tais como comerciais e de uso misto e mesmo buscar outras empresas para participar da pesquisa. Essas novas pesquisas poderiam ter como objetivo testar a robustez da proposta apresentada para fins de generalização.

Além disso, sugerem-se tentativas de validação da proposta em outras empresas. Conforme visto, ela pressupõe níveis evolutivos de colaboração e contempla um roteiro para um diagnóstico das práticas colaborativas e posterior orientação para a implantação dos princípios do TVD. A continuidade da identificação de oportunidades e barreiras para implantação do TVD é sugerida.
Como considerar as percepções de valor do usuário final e ao mesmo tempo contemplar as restrições orçamentárias para desenvolvimento do produto? Essa é uma questão de grande importância na ótica do CM/TVD, pois impacta diretamente na qualidade do produto final entregue pela empresa, bem como na aceitação e preferência dos usuários finais. $\mathrm{O}$ desenvolvimento de ferramentas e processos para identificação do valor percebido pelo usuário ainda necessita de estudos mais aprofundados para auxiliar a busca da integração do TVD na gestão do processo de projeto das empresas, justificando-se, assim, mais estudos nesta temática.

\section{Referências}

\author{
AMERICAN INSTITUTE OF ARCHITECTS. \\ Integrated Project Delivery: a guide. 2007. \\ Disponível em: \\ <http://www.aia.org/contractdocs/aias077630>. \\ Acesso em: 15 jul. 2014
}

ANSARI, S. L.; BELL, J. E. Target Costing: the next frontier in strategic cost management. Chicago: Irwin, 1997.

BALLARD, G. The Last Planner System of Production Control. Birmingham, 2000. $192 \mathrm{f}$. Tese (Doutorado) - School of Civil Engineering, The University of Birmingham, Birmingham, 2000.

BALLARD, G. Target Value Design: current benchmark. Lean Construction Journal, v. 6, n. 1, p. 79-84, 2011.

BALLARD, G.; REISER, P. The St. Olaf College Fieldhouse Project: a case study in designing to target cost. In: INTERNATIONAL GROUP FOR LEAN CONSTRUCTION, Dinamarca, 2004. Proceedings... Dinamarca, 2004.

COOPER, R.; SLAGMULDER, R. Target costing and value engineering. Portland: Productivity Press, 1997.

DENEROLLE, S. The application of Target Value Design to the Design Phase of 3 Hospital Projects. Berkeley: University of California, 2013.

DO, D. C.; BALLARD, G.; TOMMELEIN, I. Target Value Design as a Method For Controlling Project Cost Overruns. In: INTERNATIONAL GROUP FOR LEAN CONSTRUCTION, 22., Oslo, 2014. Proceedings... Oslo, 2014.

EMMITT, S. Lean Design Management. Architectural Engineering and Design Management, v. 7, n. 2, p. 67-69, 2011. 
GRILO, L.; MELHADO, S. Trends For Design and Project Management in the Brazilian Building Industry. In: CIB WORLD BUILDING CONGRESS, Toronto, 2004. Proceedings... Toronto, 2004.

JACOMIT, A. M.; GRANJA, A. D. An Investigation Into the Adoption of Target Costing on Brazilian Public Social Housing Projects.

Architectural Engineering and Design Management, v. 7, n. 2, p. 113-127, 2011.

LICHTIG, W. A. The Integrated Agreement of Lean Project Delivery. Construction Lawyer, v. 26, n. 3, summer 2006.

LIKER, J. K. The Toyota Way. In: 14 MANAGEMENT PRINCIPLES FROM THE WORLD'S GREATEST MANUFACTURER. New York: McGraw-Hill, 2004.

MACOMBER, H.; HOWELL, G.; BARBERIO, J. Target-Value Design: nine foundational practices for delivering surprising client value. The American Institute of Architects, Practice Management Digest, winter 2007.

MELHADO, S. et al. Uma Perspectiva Comparativa da Gestão de Projeto de Edificações no Brasil e na França. Gestão e Tecnologia de Projetos, São Carlos, v. 1, n. 1, nov. 2006.

NAOM, S. G. Dissertation, Research \& Writing For Construction Students. 2. ed. London: Elsevier, 2007.

PENNANEN, A.; BALLARD, G.; HAAHTELA, Y. Designing to Targets in a Target Costing Process. In: INTERNATIONAL GROUP FOR LEAN CONSTRUCTION..., 18., Haifa, 2010. Proceedings... Haifa, 2010.

PISHDAD-BOZORGI, P.; MOGHADDAM, E. H.; KARASULU, Y. Advancing Target Price and Target Value Design Process in IPD Using BIM and Risk-Sharing Approaches. In: ASSOCIATED SCHOOLS OF CONSTRUCTION ANNUAL
INTERNATION CONFERENCE, $49^{\text {th }}$, San Luis Obispo, 2013. Proceedings.... San Luis Obispo: ASC, 2014.

\section{RANKING ITC. Saiba Quem São as 100}

Maiores Construtoras de 2014. Disponível em: <http://rankingitc.com.br/ranking-itc-2014/>. Acesso em: 10 set. 2015.

ROCHA LIMA JUNIOR., J. Arbitragem de Valor de Portfólios de Base Imobiliária. Boletim Técnico da Escola Politécnica da USP, Departamento de Engenharia de Construção Civil; BT/PCC/132, São Paulo: Epusp, 1994.

RYBKOWSKI, Z. et al. Impact of Cost Constraints on Aesthetic Ranking Following Target Value Design Exercises. In: INTERNATIONAL GROUP FOR LEAN CONSTRUCTION, 19., Peru, 2011. Proceedings... Peru, 2011.

RUIZ, J. A.; GRANJA, A. D.; KOWALTOWSKI, D. C. C. K. Cost Reallocation in Social Housing Projects Considering the Desired Values of EndUsers. Built Environment Project and Asset Management, v. 4, n. 4, p. 352-367, 2014.

WOMACK, J. P.; JONES, D. T.; ROOS, D. A Máquina Que Mudou o Mundo. Campus: São Paulo, 2004.

YIN, R. K. Estudo de Caso: planejamento e métodos. 4. ed. Bookman: Porto Alegre. 2010.

ZIMINA, D.; BALLARD, G.; PASQUIRE, C. Target Value Design: using collaboration and a lean approach to reduce construction cost.

Construction Management and Economics, v. 30, p. 383-398, may 2012.

\section{Agradecimentos}

Os autores agradecem à Capes e à Fapesp pelo apoio financeiro a esta pesquisa.

\section{Carolina Asensio Oliva}

Laboratório de Gerenciamento na Construcão, Departamento de Arquitetura e Construcão, Faculdade de Engenharia Civil, Arquitetura e Urbanismo | Universidade Estadual de Campinas | Av. Albert Einstein, 951, Cidade Universitária Zeferino Vaz, Barão Geraldo | Campinas SP - Brasil | Caixa Postal 6021 | CEP 13083-852 | Tel.: (19) 3521-2082 | E-mail: carol_oliva@yahoo.com.br

\section{Ariovaldo Denis Granja}

Laboratório de Gerenciamento na Construção, Departamento de Arquitetura e Construção, Faculdade de Engenharia Civil, Arquitetura e Urbanismo | Universidade Estadual de Campinas | E-mail: adgranja@fec.unicamp.br

\section{Revista Ambiente Construído}

Associação Nacional de Tecnologia do Ambiente Construído

Av. Osvaldo Aranha, $99-3^{\circ}$ andar, Centro

Porto Alegre - RS - Brasil CEP 90035-190

Telefone: +55 (51) 3308-4084

Fax: +55 (51) 3308-4054

www.seer.ufrgs.br/ambienteconstruido

E-mail: ambienteconstruido@ufrgs.br 